\title{
Health Professionals' Intention to Leave from Public Health Facilities and Its Determinants in Gambella Region, Southwest Ethiopia
}

\author{
Adugna Endale Woldegiorgis ${ }^{1}$, Shimeles Ololo Sinkie ${ }^{2,}$, , Fikiru Tafese Jaleta ${ }^{2}$ \\ ${ }^{1}$ School of Medicine, Dire-Dawa University, Dire-Dawa, Ethiopia \\ ${ }^{2}$ Department of Health Economics, Management, and Policy, Jimma University College of Health Sciences, Jimma, Ethiopia \\ Email address: \\ adugnaendale73@gmail.com (A. E. Woldegiorgis), shimeles.ololo@ju.edu.et (S. O. Sinkie), fikretafese@gmail.com (F. T. Jaleta)
}

\section{To cite this article:}

Adugna Endale Woldegiorgis, Shimeles Ololo Sinkie, Fikiru Tafese Jaleta. Health Professionals' Intention to Leave from Public Health Facilities and Its Determinants in Gambella Region, Southwest Ethiopia. American Journal of Health Research.

Vol. 3, No. 6, 2015, pp. 386-392. doi: 10.11648/j.ajhr.20150306.22

\begin{abstract}
Background: Although the number of health facilities in Gambella region had been increasing dramatically, there were shortages of health professionals in the health facilities besides their high turnover. In spite of the existence of such problem, its magnitude \& determinants were not well known. The objective of this study was to determine the magnitude and determinants of health professionals' intention to leave from public health facilities in Gambella Region. Methodology: Facility based cross-sectional study design was employed from April 12 to 27, 2012. Eleven health centers using simple random sampling technique and Gambella hospital purposefully were selected. All (256) health professionals working in the selected facilities were included in the survey. Self administered structured questionnaire was used to collect information. The data was entered and analyzed using SPSS version 16.0. Variables which showed association in multivariate analysis was considered as final predictors of intention to leave and strength of association was measured through adjusted odd ratio. Ethical approval was obtained from Jimma University. Result: Among a total of 252 health professionals who responded to the questionnaire, $122(48.4 \%)$ had shown intention to leave their current workplace within one year. The magnitude of intention to leave was higher for those who were dissatisfied with their work $(86.2 \%)$, staff $(84.8 \%)$, salary $(78.8 \%)$, management practice (75.8\%), incentive mechanism $(75.8 \%)$, educational opportunity $(76.0 \%)$, working environment $(76.3 \%)$, and those who perceived they were not participated in decision making process $(76.0 \%)$. Final predictors of intention to leave were: educational level, satisfaction status with salary, satisfaction status with work, and perceived involvement in decision making $(\mathrm{AOR}=2.08,5.64,4.51$ and 2.44 respectively). Conclusion: There is high level of health professionals' intention to leave from public health facilities which can enormously affect the coverage and quality of health services in the region. Health care policy makers and managers should develop and institutionalize evidence based retention strategies taking into consideration the predictors of health professionals' intention to leave.
\end{abstract}

Keywords: Intention to Leave, Health Professionals, Public Health Facilities, Southwest Ethiopia

\section{Introduction}

Intention to leave is an employee's plan of predisposition to leave the organization where one is presently employed [1] and look forward to find another job in the near future [2]. Although intention to leave does not necessarily mean actual employee turnover, it has been found to be a strong predictor of actual turnover [3, 4].

Health professionals' turnover is the most pressing problem of the health system of developing countries [5].
Turnover intention of health professionals from public health facilities can be a symptom of low job satisfaction, poor management, and lack of organizational support [6, 7]. Job dissatisfaction is a primary predictor of health professionals' intention to leave $[8,9]$. Other predictors of intention to leave vary from low salaries and fringe benefits $[1,10]$, to career advancement prospects $[9,11]$, lack of involvement in decision-making, poor management, poor benefits, lack of job security, and poor recognition $[12,13]$.

Attrition of health professionals is most severe in Sub Saharan African countries. About 1.3\% of the world's health 
workers care for people who experience $25 \%$ of the global disease burden $[14,15]$. There should be optimum number and professional mix of human resource for the effective coverage and quality of the intended services [14]. In countries, like Ethiopia, having many people affected with HIV/AIDS and attrition of health workers places a 'double burden' [16]. Thus depletion of health professionals from public health facilities affects the capacity of the health system to maintain adequate coverage, access and utilization of services [17]. For public health institutions to function effectively and efficiently a well trained, motivated and well functioning health workforce must be produced, deployed, maintained, and appropriately utilized towards the goal of improving the health of the population [18].

Ethiopia, as any other sub Saharan African countries, suffers from attrition of health professionals from rural areas, in which $85 \%$ of the population lives. In 2009 , nationally the total number of health workers significantly increased to 66314; however, what had been gained over the last five years was lost [18]. The national health worker ratio per 1000 population is only 0.84 (in 2009). This result is far less than the standard set by the World Health Organization of 2.3 per 1000 population [18]. As a result, Ethiopia's health system has faced a variety of human resource problems, primarily an overall lack of personnel in key areas, which is worsened by high number of trained personnel leaving public health facilities. Furthermore, those personnel who remained are inequitably distributed between urban and rural areas. This in turn kept the health outcomes and health service indicators of the country among the worst in the world [19].

Despite the efforts of the Ethiopian government to train and deploy more than 30000 health extension workers in rural villages and to train more than 5000 health officers between 2005 and 2010, the attrition of high-level health workers has significantly compromised the health care delivery system, especially at higher delivery points $[20,21,22]$. Thus, inadequate number and mix of health workforce contributed to the general deterioration of health indicators [20,21].

Although available data from Gambella regional health bureau showed that the number of health facilities in the region had dramatically been increasing, there was still severe shortage of health professionals in public health facilities. There was also systematic disparity in the distribution of health workers between rural and urban areas in the region. Many health professionals were leaving the public health facilities for different reasons [23]. In spite of the existence of such problem, its magnitude and determinants were not well documented. Therefore the aim of this study was to determine the magnitude and determinants of health professionals' intention to leave from public health facilities in Gambella region.

\section{Method}

Facility based cross-sectional study design was employed in Public Health Facilities of Gambella Region from April 12 to May 26, 2012. Gambella, which is a capital city of the region, is located $777 \mathrm{~km}$ away in the southwest of Addis Ababa, capital of the country. The region is characterized by hot and humid climate. Administratively, the region was divided into three zones, one special woreda (district) and thirteen ordinary Woredas. In 2012, the total number of health workers in the region was about 995, including 364 health extension workers [23]. The region had 21 functional public health centers, and one hospital which provide services for more than one year. Out of these facilities, 11 health centers were randomly selected from rural districts, and the only hospital (i.e. Gambella Hospital) was automatically selected from the only city and included in the study to represent the whole region. Then all health professionals (256) working in the selected facilities were included in this study.

The study was carried out after getting approval from the ethical clearance committee of Jimma University, collage of Health Sciences. Then, permission was obtained from Gambella Regional Health Bureau (GRHB), Zonal Health Departments and Woreda Health Offices. Before commencing the interview, informed verbal consent was obtained from all study participants after explaining the objective of the study to the participants.

A structured, pre-tested and self-administrated questionnaire was used for data collection. The questionnaire was adopted from similar study conducted somewhere else in the country [24]. It has three major components: socio-demography, perception and feeling on working condition, push and pull factors. Pretest was conducted on 5\% of the main sample size in $\mathrm{Abol}$ health center that was not selected for the main study to ensure clarity and consistence of the questions.

After the completion of data collection, cleaning, editing and coding were done; then the data were entered and analyzed using SPSS version 16.0. Descriptive statistics was used. Mean and standard deviation were analyzed for continuous variables while frequency distribution was used for categorical variables. Bivariate and multivariate logistic regression analyses were run to determine the effects of independent variables on the outcome variable while simultaneously controlling for potential confounding factors. Variables which were emerged statistically significant on the bivariate analysis at $p$-value $<0.05$ were fitted in multivariate logistic regression model. Variables which showed association in multivariate analysis were considered as final predictors of intention to leave. The strength of association between different exposure variables and the outcome variable was determined by adjusted odds ratio.

\section{Result}

\subsection{Socio Demographic Characteristics of Respondents}

A total of 256 health professionals were enrolled in the study from different professional categories. Of which 252 returned the questionnaire yielding a response rate of $98.4 \%$. Among these, one hundred seventy $(67.5 \%)$ were males. The median age of respondents were 25 years, and majority (206 
(81.7\%)) were between 20 and 29 years old. About $76 \%$ of respondents were diploma and certificate holders, $52.4 \%$ were married, and $68.3 \%$ were working in health center. More than half (149) of them were nurses. The median service year of the respondents were 3 , and $40.9 \%$ had work experience of 2 years and less (Table 1).

\subsection{Magnitude of Intention to Leave}

Table 1. Socio-demographic Characteristics of Respondents in Health Professionals' Intention to Leave Public Health Facilities in Gambella Region, 2012.

\begin{tabular}{llll}
\hline Variables (n=252) & Category & Frequency & Percent \\
\hline \multirow{2}{*}{ Sex } & Male & 170 & 67.5 \\
& Female & 82 & 32.5 \\
& $20-24$ & 101 & 40.1 \\
Age Group & $25-29$ & 105 & 41.7 \\
& $30-34$ & 27 & 10.7 \\
& $\geq 35$ & 19 & 7.5 \\
Marital Status & Married & 132 & 52.4 \\
Educational level & Single* & 120 & 47.6 \\
& Certificate \& Diploma & 192 & 76.2 \\
Institution & First \& second degree & 60 & 23.8 \\
& Health Center & 172 & 68.3 \\
& Hospital & 80 & 31.7 \\
& Medical Doctor & 3 & 1.2 \\
& pharmacist/druggist & 11 & 4.4 \\
& Health Office & 27 & 10.7 \\
& Nurse & 149 & 59.1 \\
Profession & Midwife & 13 & 5.2 \\
& Lab & 38 & 15.1 \\
& technologist/technician & 8 & 3.2 \\
& Environmental Health & 3 & 1.2 \\
& Others & 103 & 40.9 \\
& $\leq 2$ & 58 & 23.0 \\
& $3-4$ & 35 & 13.9 \\
& $5-6$ & 56 & 22.2 \\
\hline
\end{tabular}

$*$ single $=$ unmarried + divorced + widowed

Table 2. Overall Magnitude of Health Professionals Intention to Leave from Public Health Facilities in Gambella Region, 2012.

\begin{tabular}{|c|c|c|c|}
\hline Variable $(n=252)$ & Category & Frequency & Percent \\
\hline \multirow{3}{*}{$\begin{array}{l}\text { Intention to leave } \\
(\mathrm{n}=252)\end{array}$} & Yes & 122 & 48.4 \\
\hline & No & 130 & 51.6 \\
\hline & NGO & 71 & 58.2 \\
\hline \multirow{4}{*}{$\begin{array}{l}\text { Destination } \\
(\mathrm{n}=122)\end{array}$} & Private & 19 & 15.6 \\
\hline & Another region & 18 & 14.8 \\
\hline & Go out of country & 8 & 6.6 \\
\hline & Other & 6 & 4.9 \\
\hline \multirow{2}{*}{$\begin{array}{l}\text { Better job opportunity } \\
\text { elsewhere after leaving } \\
(\mathrm{n}=122)\end{array}$} & Yes & 118 & 96.7 \\
\hline & No & 4 & 3.3 \\
\hline
\end{tabular}

Among the total respondents, 122(48.4\%) intended to leave the public health facilities of the region within the coming one year. With regard to their plan where to join after leaving the current health facilities, $58.2 \%$ disclosed that they planned to join NGO, $15.6 \%$ to move to another region, $14.8 \%$ to join private health institutions while the rest had other plan such as running personal businesses, leaving out of the country, or continuing their education. Among the respondents who had intention to leave, $96.7 \%$ believed that they would have better job opportunity elsewhere if they left the current institutions (Table 2).

\subsection{Magnitude of Intention to Leave Versus Socio-demographic Factors}

The magnitude of intention to leave was relatively higher in males $(50 \%)$ as compared to females $(45.1 \%)$; and the highest rate of intention to leave was reported from those of respondents with age group 20-29 (52.4\%). The magnitude was also higher in single (61.7\%), as compared to married $(36.4 \%)$ respondents. Yet again, the magnitude was higher for first and second degree holders $(60.0 \%)$ as compared to certificate and diploma holders $(44.8 \%)$. Regarding their profession, the magnitude of intention to leave was highest for medical doctors, 3 out of 3 reported intentions to leave within the coming one year, followed by pharmacy professionals and midwives with rates of $72.7 \%$ and $69.2 \%$ respectively as compared to the other professions. There were also variations with respect to differences in work experience. Accordingly, intention to leave was higher in those with work experience less than or equal to two years (56.3\%). Moreover there was difference with regard to type of health facility, relatively higher for health professionals working in health centres $(50.6 \%)$ as compared to those working in hospital (43.8\%) (Table 3).

Table 3. Magnitude of Health Professionals' Intention to Leave versus Socio-demographic Factors from Public Health Facilities in Gambella Region, 2012.

\begin{tabular}{|c|c|c|c|}
\hline \multirow{2}{*}{$\begin{array}{l}\text { Variables } \\
(\mathrm{n}=252)\end{array}$} & \multirow{2}{*}{ Category } & \multicolumn{2}{|c|}{ Intention to Leave } \\
\hline & & Yes $(\%)$ & No $(\%)$ \\
\hline \multirow{2}{*}{ Sex } & Male & $85(50.0)$ & $85(50.0)$ \\
\hline & Female & $37(45.1)$ & $45(54.9)$ \\
\hline \multirow{3}{*}{ Age Group } & $20-29$ & $108(52.4)$ & $98(47.6)$ \\
\hline & $30-39$ & $12(30.8)$ & $27(69.2)$ \\
\hline & $40-49$ & $2(28.6)$ & $5(71.4)$ \\
\hline \multirow{2}{*}{ Marital Status } & Married & $48(36.4)$ & $84(63.6)$ \\
\hline & Single & $74(61.7)$ & $46(38.3)$ \\
\hline \multirow{2}{*}{$\begin{array}{l}\text { Educational } \\
\text { level }\end{array}$} & Certificate \& Diploma & $86(44.8)$ & $106(55.2)$ \\
\hline & First \& second degree & $36(60.0)$ & $24(40.0)$ \\
\hline \multirow{8}{*}{ Profession } & Medical doctors & $3(100)$ & 0 \\
\hline & Pharmacist/druggist & $8(72.7)$ & $3(27.3 \%)$ \\
\hline & Health officers & $13(48.1)$ & $14(51.9 \%)$ \\
\hline & Nurse & $61(40.9)$ & $88(59.1 \%)$ \\
\hline & Midwife & $9(69.2)$ & $4(30.8 \%)$ \\
\hline & $\begin{array}{l}\text { Lab } \\
\text { technologist/technician }\end{array}$ & $21(55.3)$ & $17(44.7 \%)$ \\
\hline & Environmental Health & $4(50.0)$ & $4(50.0 \%)$ \\
\hline & Others & $3(100)$ & 0 \\
\hline \multirow{4}{*}{ Service Year } & $\leq 2$ & $58(56.3)$ & $45(43.7)$ \\
\hline & $3-4$ & $30(51.7)$ & $28(48.3)$ \\
\hline & $5-6$ & $14(40.0)$ & $21(60.0)$ \\
\hline & $\geq 7$ & $20(35.7)$ & $36(64.3)$ \\
\hline \multirow{2}{*}{ Institution } & Health Center & $87(50.6)$ & $85(49.4)$ \\
\hline & Hospital & $35(43.8)$ & $45(56.2)$ \\
\hline
\end{tabular}

\subsection{Magnitude of Intention to Leave Versus Push and Pull Factors}

Descriptive analysis on push and pull factors showed that, the magnitude of intention to leave was higher for those who 
were dissatisfied with their work $(86.2 \%)$, staff $(84.8 \%)$, salary $(78.8 \%)$, management practice $(75.8 \%)$, incentive $(75.8 \%)$, educational opportunity $(76.0 \%)$, working environment $(76.3 \%$,), and those who were not participated in decision making process $(76.0 \%)$ as compared to those who were satisfied with the above mentioned factors and those participated in decision making process respectively (Table 4).

\subsection{Bivariate Analysis}

Crude analysis of socio-demographic variables on binary logistic regression showed that marital status, educational level, and years of experience had statistically significant association with intention to leave at $\mathrm{p}<0.05$. While among the organizational and environmental variables (push and pull factors), status of involvement in decision making, status of existence of performance evaluation, status of satisfaction with ones work, staff, salary, management practice, incentive, educational opportunity, and working environment had shown statistically significant association with health professionals intention to leave at $\mathrm{p}<0.05$. On the other hand, age, sex, ethnicity, religion, type of facility, and profession of the respondents did not show statistically significant association with intention to leave in the bivariate analysis (Table 5).

Table 4. Magnitude of Health Professionals' Intention to Leave versus Push and Pull Factors from Public Health Facilities in Gambella Region, 2012.

\begin{tabular}{llll}
\hline \multirow{2}{*}{ Variables (n= 252) } & \multirow{2}{*}{ Category } & \multicolumn{2}{l}{ Intention to Leave } \\
\cline { 3 - 4 } & & Yes (\%) & No (\%) \\
\hline \multirow{2}{*}{ Satisfaction with Work } & Satisfied & $47(29.6)$ & $112(70.4)$ \\
& Dissatisfied & $56(86.2)$ & $9(13.8)$ \\
Satisfaction with Staff & Satisfied & $50(30.9)$ & $112(69.1)$ \\
& Dissatisfied & $56(84.8)$ & $10(15.2)$ \\
Satisfaction with Salary & Satisfied & $23(21.7)$ & $83(78.3)$ \\
Satisfaction with Management & Dissatisfied & $78(78.8)$ & $21(21.2)$ \\
System & Satisfied & $32(28.1)$ & $82(71.9)$ \\
Satisfaction with Incentive & Dissatisfied & $69(75.8)$ & $22(24.2)$ \\
Satisfaction with Educational & Satisfied & $26(25.7)$ & $75(74.3)$ \\
Opportunity & Dissatisfied & $69(75.8)$ & $22(24.2)$ \\
Satisfaction with Working & Satisfied & $27(26.0)$ & $77(74.0)$ \\
Environment & Dissatisfied & $76(76.0)$ & $24(24.0)$ \\
Involvement in Decision & Satisfied & $27(24.5)$ & $83(75.5)$ \\
Making & Dissatisfied & $74(76.3)$ & $23(23.7)$ \\
\hline
\end{tabular}

\subsection{Multivariate Analysis}

A multivariate analysis involving all associated variables was performed to identify independent predictors of intention to leave. Consequently, four variables were found to have statistically significant association with intention to leave after adjusting for confounders. Thus level of education, status of satisfaction with work and salary, and status of involvement in decision making independently showed statistically significant association. The other variables were not significant at $\mathrm{p}$-value $<0.05$.
Those health professionals whose educational level were first and second degree had 2.08 times more likely to have intention to leave from the public health facilities compared to diploma and certificate holders $(\mathrm{AOR}=2.82,95 \% \mathrm{CI}$ : $1.69,4.69)$. In addition, those of respondents who were dissatisfied with their work and salary had 4.51 and 5.64 times more likely to show intention to leave public health facilities as compared to those who were satisfied with their work and salary respectively (95\% CI: 1.844, 12.366, and $2.216,11.386$ respectively). Moreover, respondents who were not involved in decision making had 2.44 times more likely intention to leave from the public facilities compared to those who participated in decision making $(\mathrm{AOR}=2.58,95 \% \mathrm{CI}$ : $1.12,5.92$ ) (Table 6).

Table 5. Socio-demographic, push and pull factors showing association with health professionals' intention to leave from public health facilities in Gambella Region, Southwest Ethiopia, 2012.

\begin{tabular}{|c|c|c|c|c|c|}
\hline \multirow[t]{2}{*}{ Variables $(n=252)$} & \multicolumn{2}{|c|}{$\begin{array}{l}\text { Intention to } \\
\text { Leave }\end{array}$} & \multirow{2}{*}{$\begin{array}{l}\text { Crude } \\
\text { OR }\end{array}$} & \multicolumn{2}{|c|}{$95 \% \mathrm{CI}$} \\
\hline & Yes & No & & Lower & Upper \\
\hline \multicolumn{6}{|l|}{ Marital status } \\
\hline Married* & 48 & 84 & 1.00 & & \\
\hline Single & 74 & 46 & 2.82 & 1.69 & 4.69 \\
\hline \multicolumn{6}{|l|}{ Educational level } \\
\hline Certificate and dip* & 86 & 106 & 1.00 & & \\
\hline First and $2^{\text {nd }}$ degree & 36 & 24 & 1.85 & 1.03 & 3.33 \\
\hline \multicolumn{6}{|l|}{ Years of experience } \\
\hline$\leq 2 *$ & 58 & 45 & 1.00 & & \\
\hline $3-4$ & 30 & 28 & 0.83 & 0.44 & 1.59 \\
\hline $5-6$ & 14 & 21 & 0.52 & 0.24 & 1.13 \\
\hline$\geq 7$ & 20 & 36 & 0.43 & 0.22 & 0.84 \\
\hline \multicolumn{6}{|l|}{ satisfaction with work } \\
\hline Satisfied* & 47 & 112 & 1.00 & & \\
\hline Dissatisfied & 56 & 9 & 14.83 & 6.78 & 32.41 \\
\hline \multicolumn{6}{|l|}{ satisfaction with staff } \\
\hline Satisfied* & 50 & 112 & 1.00 & & \\
\hline Dissatisfied & 56 & 10 & 12.54 & 5.92 & 26.58 \\
\hline \multicolumn{6}{|l|}{ satisfaction with salary } \\
\hline Satisfied* & 23 & 83 & 1.00 & & \\
\hline Dissatisfied & 78 & 21 & 13.40 & 6.87 & 26.13 \\
\hline \multicolumn{6}{|l|}{ satisfaction with mgt } \\
\hline Satisfied* & 32 & 82 & 1.00 & & \\
\hline Dissatisfied & 69 & 22 & 8.04 & 4.28 & 15.09 \\
\hline \multicolumn{6}{|l|}{ satisfaction with incentive } \\
\hline Satisfied* & 26 & 75 & 1.00 & & \\
\hline Dissatisfied & 69 & 22 & 9.05 & 4.70 & 17.42 \\
\hline \multicolumn{6}{|l|}{ satisfaction with educ. } \\
\hline Satisfied* & 27 & 77 & 1.00 & & \\
\hline Dissatisfied & 76 & 24 & 9.03 & 4.79 & 17.04 \\
\hline \multicolumn{6}{|l|}{$\begin{array}{l}\text { satisfaction with working } \\
\text { environment }\end{array}$} \\
\hline Satisfied* & 27 & 83 & 1.00 & & \\
\hline Dissatisfied & 74 & 23 & 9.89 & 5.22 & 18.73 \\
\hline \multicolumn{6}{|l|}{$\begin{array}{l}\text { Existence of performance } \\
\text { evaluation }\end{array}$} \\
\hline Yes* & 52 & 82 & 1.00 & & \\
\hline No & 70 & 48 & 2.30 & 1.39 & 3.81 \\
\hline \multicolumn{6}{|l|}{$\begin{array}{l}\text { Involvement in decision } \\
\text { making }\end{array}$} \\
\hline Yes* & 84 & 118 & 1.00 & & \\
\hline No & 38 & 12 & 4.45 & 2.19 & 9.02 \\
\hline
\end{tabular}

* Reference category 
Table 6. Socio-demographic, Push and Pull Factors Determining Health Professionals' Intention to Leave Public Health Facilities in Gambella Region, 2012.

\begin{tabular}{|c|c|c|c|c|}
\hline \multirow{2}{*}{$\begin{array}{l}\text { Variables } \\
(n=252)\end{array}$} & \multicolumn{2}{|c|}{$\begin{array}{l}\text { Intention to } \\
\text { Leave }\end{array}$} & \multirow{2}{*}{$\begin{array}{l}\text { Crude OR } \\
(95 \% \mathrm{CI})\end{array}$} & \multirow{2}{*}{$\begin{array}{l}\text { Adjusted OR } \\
(95 \% \mathrm{CI})\end{array}$} \\
\hline & Yes & No & & \\
\hline \multicolumn{5}{|l|}{ Educational level } \\
\hline Certificate and dip* & 86 & 106 & 1.00 & \\
\hline First and $2^{\text {nd }}$ degree & 36 & 24 & $\begin{array}{l}1.85 \\
(1.03,3.33)\end{array}$ & $\begin{array}{l}2.08 \\
(1.01,4.28)\end{array}$ \\
\hline \multicolumn{5}{|l|}{ Satisfaction with work } \\
\hline Satisfied* & 47 & 112 & 1.00 & \\
\hline Dissatisfied & 56 & 9 & $\begin{array}{l}14.83 \\
(6.78,32.41)\end{array}$ & $\begin{array}{l}4.51 \\
(1.74,11.75)\end{array}$ \\
\hline \multicolumn{5}{|l|}{ Satisfaction with salary } \\
\hline Satisfied* & 23 & 83 & 1.00 & \\
\hline Dissatisfied & 78 & 21 & $\begin{array}{l}13.40 \\
(6.87,26.13)\end{array}$ & $\begin{array}{l}5.64 \\
(2.43,13.10)\end{array}$ \\
\hline \multicolumn{5}{|l|}{$\begin{array}{l}\text { Involvement in decision } \\
\text { making }\end{array}$} \\
\hline Yes* & 84 & 118 & 1.00 & \\
\hline No & 38 & 12 & $\begin{array}{l}4.45 \\
(2.19,9.02)\end{array}$ & $\begin{array}{l}2.44 \\
(1.06,5.61)\end{array}$ \\
\hline
\end{tabular}

* Reference category

\section{Discussion}

The results of this study indicated that $48.4 \%$ of the health professionals reported intention to leave from the public health facilities of Gambella Regional State within the coming one year. This proportion is higher as compared to a study conducted in Jimma University specialized hospital (15.4\%) [25]. This might be attributed to the climatic condition and geographical location of the region, which is far from capital city and characterized by hot weather condition. Majority of the participants who indicated an intention to leave the public health facilities of the region prefer to join NGOs (58\%), other region (18\%) and private sectors (16\%). A study done in Eastern Ethiopia and Jimma University Specialized Hospital (southwest Ethiopia) also showed that private health sectors and NGOs were the most common destinations of health professionals after leaving the public health facilities $[24,25]$. This might be due to the existence of attractive salary and incentive in NGOs and private sectors as compared to public health facilities. This is supported by the fact that about $96.7 \%$ of those health professionals who reported intention to leave perceived that there would be better job opportunity elsewhere if they left the current institution.

Findings from multivariate analysis revealed that educational level, status of satisfaction with work, and salary and status of involvement in decision making process were found to be an independent predictor of intention to leave from public health facilities after adjusting for confounders. The other variables were not significant at $5 \%$ level of significance.

The result shows that as the level of education increases the rate of intention to leave also increases significantly. Respondents with first and second degree were nearly two times more likely to show intention to leave as compared to those with certificate and diploma holders. A study conducted in Uganda also showed that health professionals with higher level of education were more likely show intention to leave as compared to less qualified professionals [26]. In addition, a study conducted in rural parts of South Africa also revealed a direct relationship between level of education and magnitude of intention to leave [27]. This might be due to the fact that health professionals with higher educational qualification (first and/or second degree holders) had better job opportunity as compared to those with less educational qualification since advancement in quality of education increases job opportunity [28].

This study also showed that those health professionals who were dissatisfied with their work were nearly four and half times more likely to show intention to leave as compared to those who were satisfied with their existing work. The study conducted in Jimma University Specialized Hospital confirmed that $57 \%$ of health professionals who showed intention to leave were dissatisfied with their work [25]. On top of this, our finding also depicted that those who were not satisfied with their salary had more than five and half times more likely to show intention to leave as compared to those who were satisfied with their salary. Likewise, a study conducted in Uganda revealed that those dissatisfied with their salary were twofold more likely to show intention to leave as compared to their counterpart [26]. When employees, including health professionals were found to be more satisfied, they would usually show more commitment to the organization and the profession, and ultimately, have a lower tendency of leaving $[29,30]$. The study by Zeytinoglu et al. [29] demonstrated that health professionals who intended to leave had lower satisfaction scores than health professionals with intention to stay.

Moreover the results of this study showed that, respondents who were not involved in decision making were almost two and half times more likely to show intention to leave the public health facilities compared to those who participated in decision making. This fact is further evidenced by the study conducted in Uganda which revealed that active involvement in the decision making process reduces the odds of intention to leave from public health facilities [26]. Lack of involvement in decision making plays an important role in workforce stability, and it has also been confirmed in other study [31].

\section{Conclusion}

There is high level of health professional's intention to leave from public health facilities of Gambella Regional State which can enormously affect the quality and coverage of health services in the region. Educational level, satisfaction status with work, satisfaction status with salary, and status of involvement in decision making process appeared to be independent predictors of health professionals' intention to leave. Thus, health professionals who were more likely stay in the public health facilities were less qualified with their education, those who satisfied with 
their work and salary and those involved in decision making process.

Hence health care policy makers and managers should develop and institutionalize evidence based health professionals' retention strategies taking into consideration the predictors of health professionals' intention to leave. On top of this, there is a need for further research to identify specific concerns which motivate health professionals' to retain in their current workplace for further interventions.

\section{Acknowledgements}

The authors thank all the study participants.

\section{References}

[1] Hayes LJ, O'Brien-Pallas L, Duffield C, shamian J, Buchan J, Hughes F, Laschinger HKS, North N, Stone PW, (2006). Nurse turnover: A literature review. Int J Nurs Stud; 43:237263.

[2] Muhammad, M. A., Jamilha F. M., (2010). Level of job satisfaction and intent to leave among Malaysian nurses. Business Intelligence Journal; 3:124-135.

[3] Rahim MA, Psenicka C, (1996). A structural equations model of stress, locus of control, social support, psychiatric symptoms, and propensity to leave a job. J Soc Psychol; 136:69-84.

[4] Griffeth RW, Hom PW, Gaertner S., (2000). A meta-analysis of antecedents and correlates of employee turnover: Update, moderator tests, and research implications for the next millennium. J Manage; 26:463-488.

[5] Yumkella F., (2006). Retention of Health Care Workers in Low-Resource Settings: Challenges and Re-sponses. Capacity project; 1:1-6.

[6] Zurn, P., Dolea, C., Stillwell, B., (2005). Nurse retention and recruitment: developing a motivated workforce, in the global nursing review initiative. International Council of Nurses.

[7] Fridrkin S., Pear S., Williamson T., (1996). The role of understaffing in central venous catheter association blood stream infection. Infect control Hosp epidemic; 17:150-158.

[8] Shields, M.A., \& Ward, M., (2001). Improving nurse retention in the National Health Service in England: the impact of job satisfaction on intention to quit. Journal of Health Economics, 20:677-701.

[9] Tzeng, H.M., (2002). The influence of nurses' working motivation and job satisfaction on intention to quit: an empirical investigation in Taiwan. International Journal of Nursing Studies; 39:867-878.

[10] Coomber, B., \& Barriball, L. K., (2007). Impact of job satisfaction components on intent to leave and turnover for hospital-based nurses: a review of the research literature. International Journal of Nursing Studies; 44:297-314.

[11] Rambur, B., Val Palumbo, M., McIntosh, B., \& Mongeon, J., (2003). A Statewide Analysis of RNs' Intention to Leave their Position. Nursing Outlook; 51:181-188.
[12] Albaugh, J., (2003). Keeping nurses in nursing: the profession's challenge for today. Urologic Nursing; 23:19399.

[13] Aiken, L. H, Sloane, D, M., \& Lake, E., (1997). Satisfaction with Inpatient Acquired Immunodeficiency Syndrome Care: A National Comparison of Dedicates and Scattered-Bed Units. Medical Care; 35:948-962.

[14] Working Together for Health: WHO Report, (2006a). Available at www.who.int/whr/2006/ en/ (accessed on November 21/2011).

[15] World Health Organization Report. Part 2, (2006b): Global Health Indicators http://www.who.int/whosis/whostat/EN_WHS08. (accessed on June 21/2011).

[16] McCoy, D., McPake, B., and Mwapasa, V., (2008). The double burden of human resource and HIV crises: a case study of Malawi. Human Resources for Health 2008, 6:16. Accessed 16 December 2011 at: http://www.human-resourceshealth.com/content/6/1/16 (accessed on December 12/2011).

[17] ICN, (2001). Nurse Migration, International Council for Nursing, Geneva, Switzerland.

[18] Global Health Workforce Alliance/World Health Organization, (2010). Ethiopia's Human Resources for Health Program report.

[19] Ethiopian Federal Ministry of Health, (2005). Health Sector Development Program III report.

[20] Dovlo, D. Y., (1999). Report on Issues Affecting the Mobility and Retention of Professionals in Commonwealth African States, Unpublished Report for Commonwealth Secretariat Technical Support Group.

[21] Dovlo D.Y., (2002). Retention and deployment of health workers and professionals in Africa, paper presented at consultative meeting on improving collaboration between health professionals and governments in policy formulation and implementation of health sector reform. Addis Ababa.

[22] Dovlo D.Y., (2003). The brain drain and retention of health professionals in Africa, case study for regional training conference: 'Improving tertiary education in sub-Saharan Africa: Things that work'. Accra, 23-25 September. World Bank: Switzerland, available on 28 July 2007 at: www.worldbank.org/afri/teia/0903/dela dolvo.pdf (accessed on September 16/2011).

[23] Gambella Region Health Bureau, (2011). Annual report.

[24] Jundi A., (2008). Assessment of the magnitude, patterns and determinant factors of health worker migration from the public health sectors: A descriptive case study in East Hararghe zone of Oromiya, Eastern Ethiopia (unpublished).

[25] Yami A, Hamza L, Hassen A, Jira C, Sudhakar M, (2011). Job satisfaction and its determinants among health workers in Jimma University specialized hospital, southwest Ethiopia. Ethiop J. Health Sci.; 2021:19-26.

[26] Hagopian A, (2007). Uganda Facility Based Health Workforce Study: Satisfaction and Intent to Stay Among Current Health Workers. Human Resources for Health; 4:1-10.

[27] Delobelle P, Rawlinson JL, Ntuli S, Malatsi I, Decock R, Depoorter AM, (2011). Job satisfaction and turnover intent of primary healthcare nurses in rural South Africa: a questionnaire survey. J Adv Nurs; 67:371-383. 
[28] Oakleigh Consulting Ltd and CRAC, (2011). Increasing opportunities for high quality higher education work experience. Report to HEFCE, available at www.oakleigh.com (accessed on August/22/2011).

[29] Zeytinoglu IU, Denton M, Davies S, Baumann A, Blythe J, Boos L, (2006). Retaining nurses in their employing hospitals and in the profession: Effects of job preference, unpaid overtime, importance of earnings and stress. Health Policy; 79:57-72.
[30] Steel R, (2002). Turnover theory at the empirical interface: problem of fit and function. Academy of Management; 27:346-60.

[31] Bowers, B.J., Esmond, S. \& Jacobson, N., (2000). The relationship between staffing and quality in long-term care facilities: Exploring the views of nurse aides. J Nurs Care Qual, 14:55-64. 